\title{
Evaluation of groundwater potential in part of Ahmadu Bello University, Zaria, Northwest Nigeria
}

\author{
Obihan Ifeanyi ${ }^{1}$ - Ameloko Anthony Aduojo ${ }^{2}$ (I) $\cdot$ Kalejaiye F. Olaide ${ }^{3} \cdot$ Ngozi-Chika C. Stephen $^{1}$. \\ Rotimi Oluwatosin John²
}

Received: 4 September 2020 / Accepted: 12 January 2021 / Published online: 8 February 2021

(c) The Author(s) 2021 OPEN

\begin{abstract}
The need to address the acute water shortage problem within the Ahmadu Bello University Zaria Campus in Samaru necessitated this groundwater exploration project. 2D geoelectric imaging and vertical electrical sounding (VES) surveys were carried out to investigate the groundwater potential of the study area. The 2D geoelectric models and sounding curves obtained were correlated with existing borehole logs obtained from the area, hence validating the results from the $2 \mathrm{D}$ resistivity survey. Results from the surveys showed three-layer lithologies with varying thicknesses and resistivity values. The topsoil showed resistivity values of between 4 and $170 \Omega \mathrm{m}$, characteristic of clayey sand and sandy materials. The second layer is characterized by resistivity values ranging between $<4$ and $90.6 \Omega \mathrm{m}$, coinciding with zones of the weathered basement. The third layer which has resistivity values ranging between 90 and $550 \Omega \mathrm{m}$ constitutes the basement rocks. The thicknesses of the weathered regoliths favourable for groundwater exploration vary from $13.4 \mathrm{~m}$ around the Amina Hall, $16.7 \mathrm{~m}$ northeast-southwest of Akenzua Hall, $21.2 \mathrm{~m}$ northwest-southeast of Akenzua Hall, $24.3 \mathrm{~m}$ around Alex Hall and $25.3 \mathrm{~m}$ around the Suleiman Hall. These very important parameters reveal the groundwater potential of the study area and therefore suggest that groundwater can be developed and harnessed for use by the University but with a greater yield around the Alex and Suleiman Halls. VES survey was integrated with the 2D resistivity survey to provide information that compliment results from the $2 \mathrm{D}$ resistivity survey. The sounding curves were A-Type and $\mathrm{H}$-type curves exhibiting low resistivity values $(5-24 \Omega \mathrm{m})$ within the second layer.
\end{abstract}

Keywords Geoelectric · Profiles · Correlation · Resistivity values · Basement rock

\section{Introduction}

Groundwater is a crucial resource used as an alternative source for drinking water [17] and also a viable source for meeting domestic water needs such as bathing, cooking, and washing. This can be attributed to the fact that it is safe, economical, available and is generally more protected from contamination as compared to surface water [25]. Generally, groundwater is not too hard to locate in Zaria environ in terms of depth, as the water table is within a few meters below the surface of the ground. However, the yield of boreholes is frequently low and water supplies do not have long-term sustainability [14]. This challenge is attributed to a lack of geophysical or inadequate geophysical investigation before the citing of boreholes.

Resistivity survey aims to investigate the subsurface resistivity distribution by carrying out measurements on the surface of the ground. From these measurements, the true electrical property of the subsurface can be revealed. The method involves sending electrical currents into the subsurface via two current electrodes, while the electrical potential difference is measured between two other potential

Ameloko Anthony Aduojo, tonyameloko@yahoo.com | ${ }^{1}$ Department of Earth Sciences, Salem University, Lokoja, Nigeria. ${ }^{2}$ Department of Petroleum Engineering, Covenant University Ota, Ota, Nigeria. ${ }^{3}$ Biotite Geosciences and Engineering Ltd, Kaduna, Nigeria. 
electrodes along a predetermined profile. This process is repeated in a systematic manner such that for many different combinations of source and receiver, data-set is obtained from such an operation to enable the construction of a crosssection through the survey area. The resulting cross-section of the subsurface represents a spatial distribution of resistivity, which is closely linked with the internal architecture of the body. The electrical characteristics of various geological substances enable geoscientists to noninvasively image structures in the subsurface. The ground electrical property is related to the different geological properties such as the porosity and degree of water saturation in the rock, and mineral and fluid content.

The electrical resistivity techniques are increasingly being employed in the study and evaluation of groundwater potential and mining survey [22], geotechnical investigation, environmental contamination and geological mapping $[6,8,10,19]$. The method is usually deployed in contamination study as a result of their ability to discriminate between areas free of contamination and the contaminated zones [7]. Improved technology over time led to the development of electrical resistivity Tomography or electrical imaging tools with 3D and 2D data interpretations. With this new development, the subsurface property is unraveled and improves better knowledge of the geologic situation. Other areas of application of resistivity techniques are being developed as knowledge improves and challenges in many areas of human endeavour called for an audience.

As a result of the rapidly growing population and the pressure on the existing borehole facilities within the Ahmadu Bello University community, Samaru Campus, there was a need for intensive groundwater prospecting on campus to address the problem of acute water shortage faced by residents of the University. This geophysical survey was therefore designed to explore the groundwater potential within the campus to guide the University on the appropriate locations to site boreholes. Since 2D electrical imaging gives more detailed information on the subsurface geology, the present survey was structured to obtain appropriate images of the study area to delineate appropriate locations for groundwater exploitation. In doing this, an attempt was made to establish a correlation between geologic and geoelectric information from the area under investigation. It is hoped that this information would enhance the success rate of future groundwater exploration and exploitation in the area.

\section{Location and geology of the study area}

The study site is located within the Ahmadu Bello University main campus in Zaria (Fig. 1). It is approximately bounded by latitude $11^{\circ} 09^{1} \mathrm{~N}$ and $11^{\circ} 10^{1} \mathrm{~N}$ longitude $7^{\circ} 38^{1} \mathrm{E}$ and $7^{\circ} 39^{1} \mathrm{E}$. It is a part of the gently undulating peneplain that extends from Lake Chad to Sokoto and Northward from Southern Kaduna into the Republic of Niger. The slope within the Zaria environment is generally less than $4^{\circ}$ with the exception of those of inselbergs, lateritic mesas and river valleys. Two distinct seasons are identifiable in the Zaria area, and they are the dry and rainy seasons. The wet season lasts from April to October, with the maximum rainfall in August. Zaria has a mean annual rainfall of $1082 \mathrm{~mm}$ [15]. Land use/cover change assessed by Aminu et al. [9], through a time-series analysis of Landsat Thematic Mapper 1990, Enhanced Thematic Mapper +,1999 and NigeriaSat-1 2009 satellite imageries of the study area suggests that the major changes in land use/cover were in the plantation and cultivated areas with very significant increase in areal extent by ( $19.8 \%$ and $13.8 \%$ gain, respectively) while cultivated land and water bodies depreciated with a loss of about $386 \mathrm{~km}^{2}(-2.73 \%$ loss $)$ and $20.7 \mathrm{~km}^{2}(-5.5 \%$ loss). Zaria is underlain by Precambrian rocks typical of Nigeria basement complex, which bear the imprint of thermo-tectonic event dating from Achaean to early Paleozoic times [18]. The study location is underlain by Precambrian rocks of the basement complex with muscovite biotite-gneiss in the south-western part of the campus, while the north-eastern part is underlain by biotite granite-gneiss [12]. The entire area is generally underlain in part by Pre-Cambrian rocks which lie in the mobile zone between the West African and Congo cratons (Fig. 2). These Pre-Cambrian rocks are made up of gneisses, migmatites and metasedimentary rocks trending north-south and intruded by a series of maficultra-mafic and granitic rocks of late Pre-Cambrian to early Palaeozoic age as reported by McCurry, [18]. The summary of the hydrogeological findings according to the works of Danladi, [11], Alagbe, [5] and Adanu, [1] is as follows,

- Fresh crystalline rocks contain no water.

- Two types of aquifers, the fractured rock and regolith aquifers are present,

- The specific yield of boreholes was observed to be similar in all rock types probably because the regolith aquifer of the different rocks possesses similar hydraulic properties. To successfully sink a borehole in a crystalline environment like Zaria where the groundwater aquifer is fairly complex and heterogeneous, there is the need for a thorough investigation of the subsurface geology and hydrogeology in considerable details. Long time in-place breakdown of the basement complex rocks under tropical climates often time produces a sequence of unconsolidated sediments that are usually extensive and of varying 


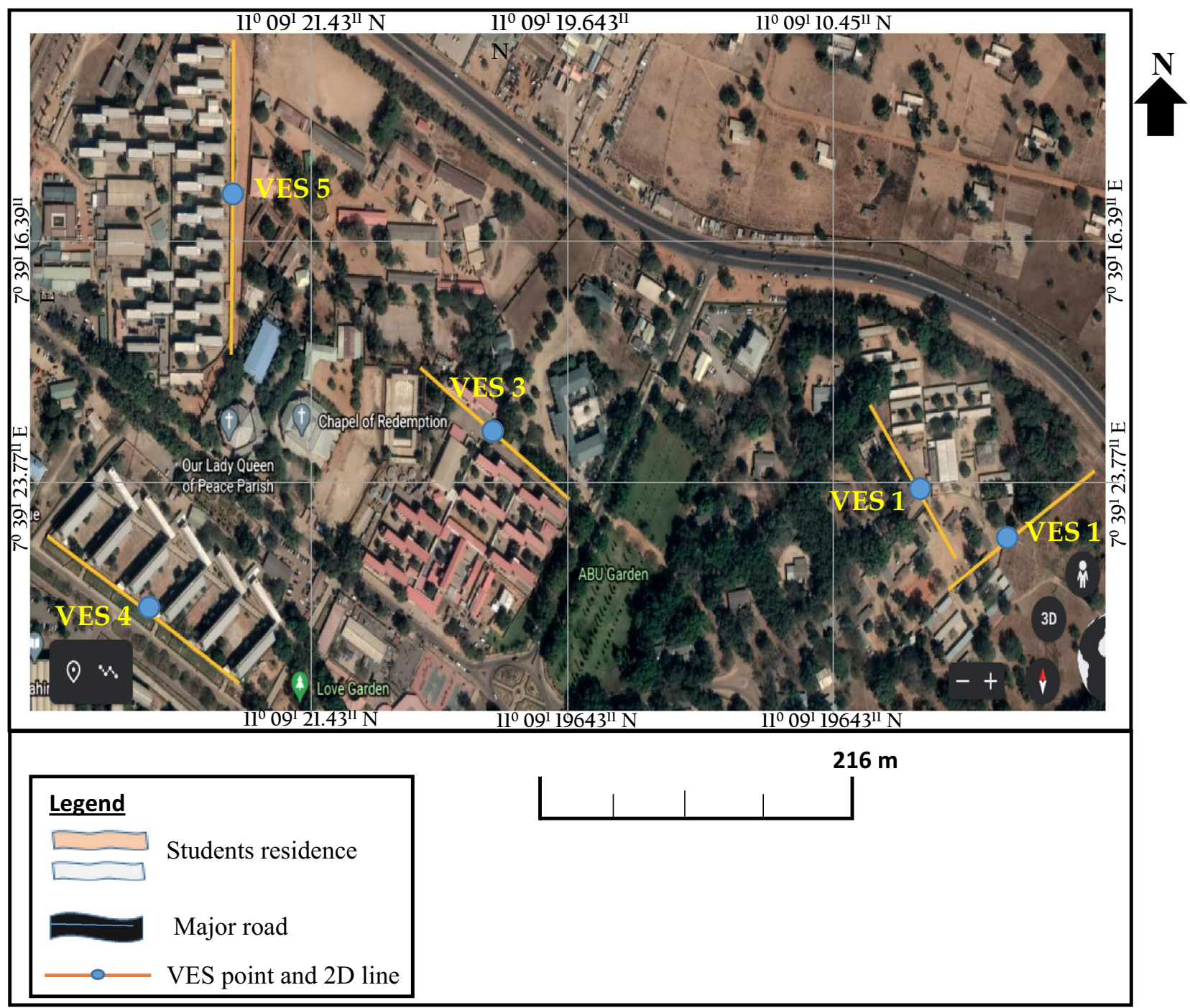

Fig. 1 Map of Study Location (Samaru Campus A.B.U. Zaria) showing Profiles

thicknesses. The occurrence of groundwater around such zones is determined by several parameters which include the extent and pattern of weathering, the depth, parent rock type, the sand/clay ratio, thickness of the weathered materials, and the degree of fracturing, fissuring and jointing [24]. It is vital that the hydrogeological parameters of the rocks are well investigated and interpreted for adequate groundwater development, modeling, well design and construction especially for localities lacking such useful information [2].

\section{Materials and method}

The $2 \mathrm{D}$ resistivity study was accomplished with the aid of a multi-electrode Lund imaging instrument, SAS 4000. The resistivity parameters were obtained along predetermined profiles using the Wenner array, with $5 \mathrm{~m}$ spacing between 40 copper steel electrodes. The length of each profile along the predetermined line was $200 \mathrm{~m}$. The choice of the Wenner configuration was because of its advantage to provide good vertical resolution and clear image for groundwater and sand-clay boundaries as horizontal structures [3]. The borehole logs with which the 2D images were constrained were obtained from Hydro-Skill engineering services limited around the area. The digital measuring instrument, together with an electrode selector, was used to select the relevant four electrodes for each 


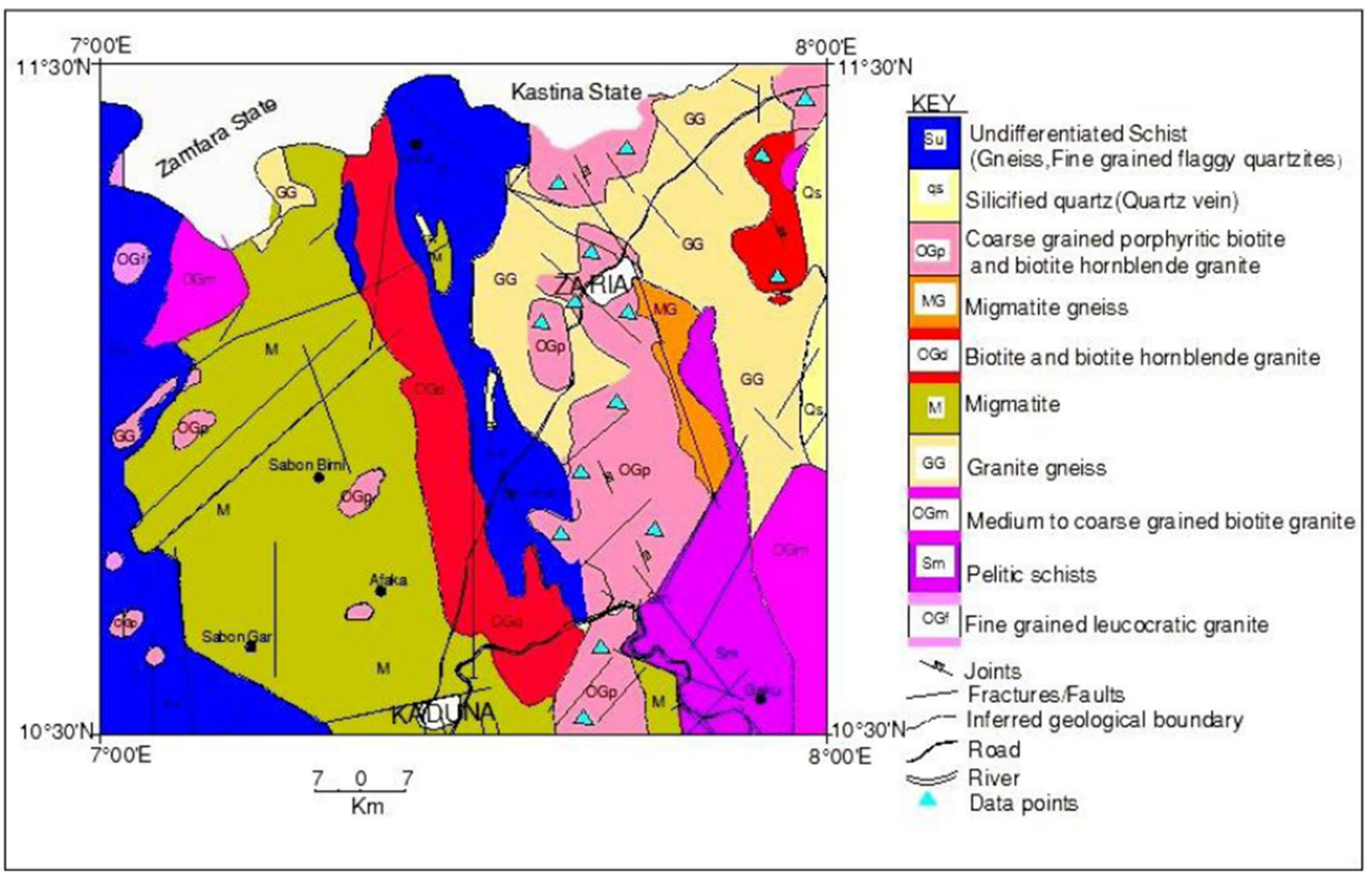

Fig. 2 Geological map of study area. Source [20]

measurement automatically. The type of configuration to use, the sequence of measurements to take, and other survey parameters were imputed into a text file that can be read by a computer program in a laptop computer. With the aid of the software, the appropriate electrodes for each measurement were then automatically selected. During the survey, the data set was obtained automatically and stored in the measuring instrument, where they were later retrieved for further processing. The data were processed and inverted using the RES2DINV.EXE inversion algorithm. The algorithm calculates the apparent resistivity values using finite difference forward modeling and quasi-Newton technique. It produces the inverted resistivity-depth image for each profile based on an iterative smoothness constrained least-squares inversion algorithm [16].

VES survey was integrated with the $2 \mathrm{D}$ resistivity survey to provide information that compliment results from the $2 D$ resistivity survey. To achieve this, five VES profiles were measured along the $2 \mathrm{D}$ resistivity lines employing the Schlumberger spread, with the midpoint of spread coinciding with the middle of the $2 \mathrm{D}$ resistivity line (Fig. 1). The partial curve matching technique was utilized for processing and interpretation of the VES curves. Thereafter, the sounding parameters were further processed using the
WINRESIST computer software to smoothen the curves and also carrying out iteration to get the curves of the best fit to the theoretical models. The layer parameters (thickness, depth and resistivity) derived were used to generate the geoelectric sections.

\section{Theory of the method used}

In practical resistivity survey, we have a bi-polar arrangement of electrodes where current goes in at one point and goes out through another, the potential at any point due to such arrangement is given as shown in the Schlumberger configuration in Fig. 3.

Since the distance between the two point current electrodes is finite, both will contribute to the potential at any nearby surface point. Therefore, the potential at $P_{1}$ due to both current electrodes is;

$U_{1}=\frac{I \rho}{2 \pi}\left(\frac{1}{r_{1}}-\frac{1}{r_{2}}\right)$

If a second potential electrode is introduced at $P_{2}$ 
Fig. 3 Schlumberger electrode configuration
$2 \mathrm{~L}$
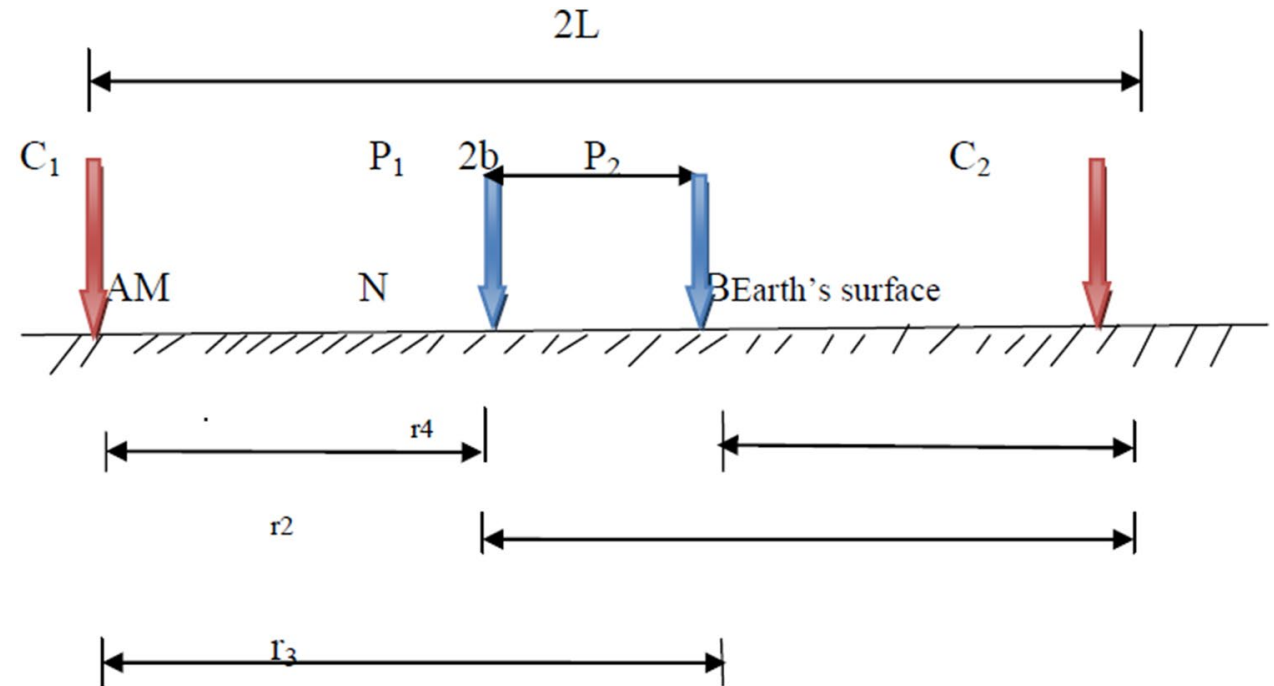

$U_{2}=\frac{l \rho}{2 \pi}\left(\frac{1}{r_{3}}-\frac{1}{r_{4}}\right)$

Then, the potential difference between $p_{1}$ and $p_{2}$ will be;

$\Delta U=\frac{I \rho}{2 \pi \pi}\left\{\left(\frac{1}{r_{1}}-\frac{1}{r_{2}}\right)-\left(\frac{1}{r_{3}}-\frac{1}{r_{4}}\right)\right\}$

In practice, there is a flow of current when there is potential gradient. When one potential electrode is used, there no potential difference established. Hence, four electrodes are used in normal resistivity surveys. Current flow between two current electrodes is measured and a receiver measures in potential difference.

From Eq. 2;

$\rho=\frac{\Delta U}{l} \cdot \frac{2 \pi}{\left\{\left(\frac{1}{r_{1}}-\frac{1}{r_{2}}\right)-\left(\frac{1}{r_{3}}-\frac{1}{r_{4}}\right)\right\}}$

Or

$\rho_{\mathrm{a}}=K \frac{\Delta U}{l}$

Where $K=\frac{2 \pi}{\left\{\left(\frac{1}{r_{1}}-\frac{1}{r_{2}}\right)-\left(\frac{1}{r_{3}}-\frac{1}{r_{4}}\right)\right\}}$

$K=$ Geometric factor which depends on the type of electrode array used.

By measuring $\Delta U$ and $I$ and knowing the electrode configuration, resistivity, $\rho$ can be calculated.

\section{Results from the experiments}

Figure 4 shows the inverted 2D resistivity model of the heterogeneous subsurface obtained on profile 1, trending northeast-southwest of the Akenzua Hall. Figure $4 a$ and $b$ represents the observed data plotted as a measured apparent resistivity pseudosection and the calculated apparent resistivity pseudosection, respectively, while Fig. 4c shows the model displaying the inverse model resistivity section (true formation resistivity and true depth). The measured and calculated apparent resistivity pseudosections for all the models give a good true representation of the subsurface, as reflected in their Root Mean Square (RMS) values. The first layer on the geoelectric model is characterized by resistivity values ranging between 19 and $100 \Omega \mathrm{m}$. This unsaturated topsoil, when constrained with available lithology log (obtained from Hydro-Skill engineering services limited around the area) at the centre of the line (Figs. 4 and 5), is made up of reddish-brown clay and sand. The $2 \mathrm{D}$ section shows greater thickness of the topsoil from the beginning of the profile to the centre, as reflected in the low resistivity values. The thickness of this layer varies from 5 to $8 \mathrm{~m}$. The second layer indicates resistivity values ranging between 30 and $50 \Omega \mathrm{m}$. The layer is interpreted as the weathered basement made up of greyish brown sandy clay and classified as an aquifer favourable for groundwater exploration. This layer exists between the depth range of $8 \mathrm{~m}$ and $18 \mathrm{~m}$, and it is being recharged through the overlying layered sediments. The third layer, like the first and second, has varying resistivity values ranging between 90 and $150 \Omega \mathrm{m}$. This is attributed to the fresh basement. The high resistivity structure is prominently displayed at the base of the model and occurs as a basement rise from a distance of about $110 \mathrm{~m}$ to the end of the profile. The variation of the thickness of this basement structure across 


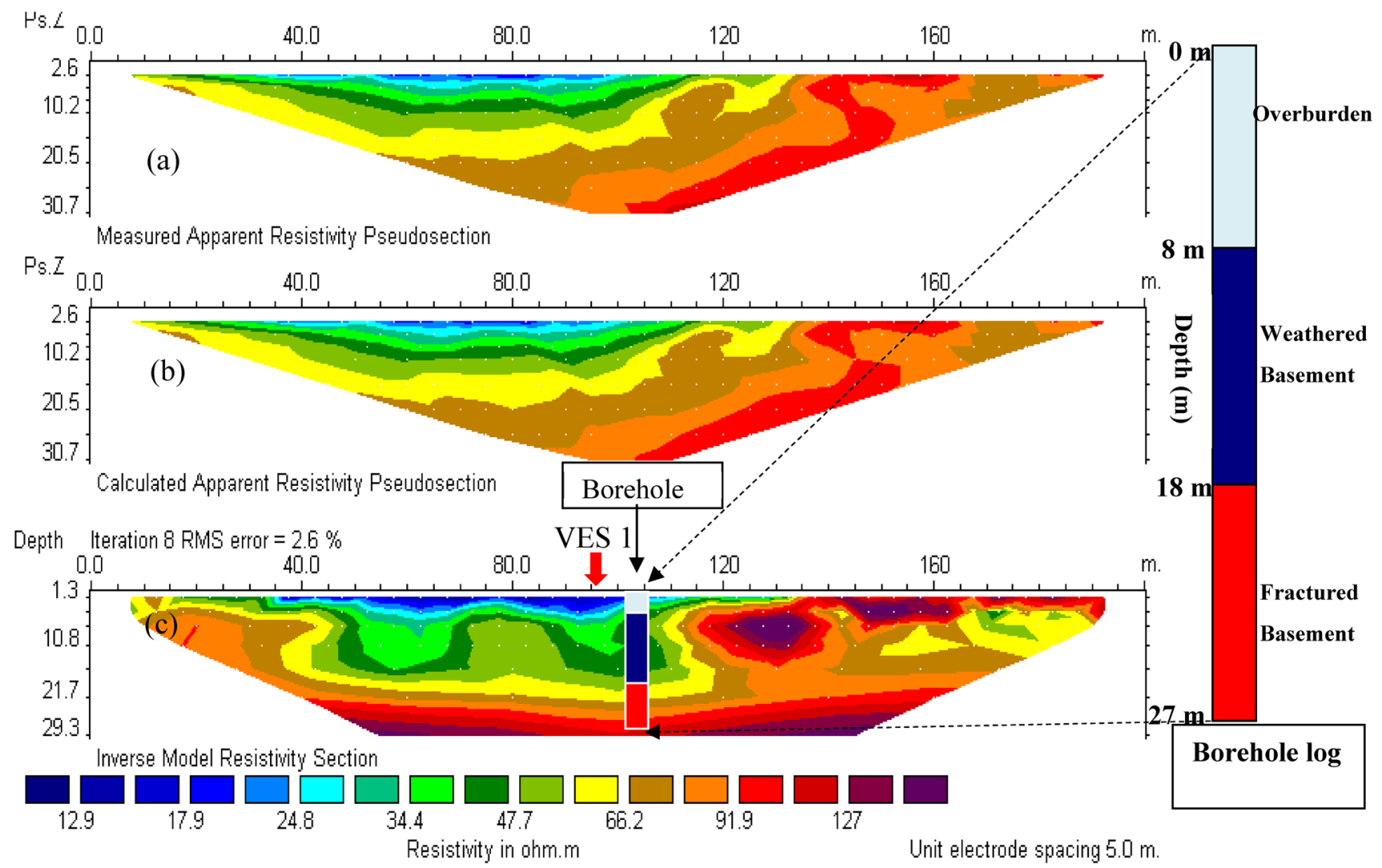

Fig. 4 Electrical imaging line on profile 1, with borehole-log at the centre (a) observed data plotted as a contoured pseudosection (b) pseudosection computed from the model and (c) image showing true formation resistivity and true depth

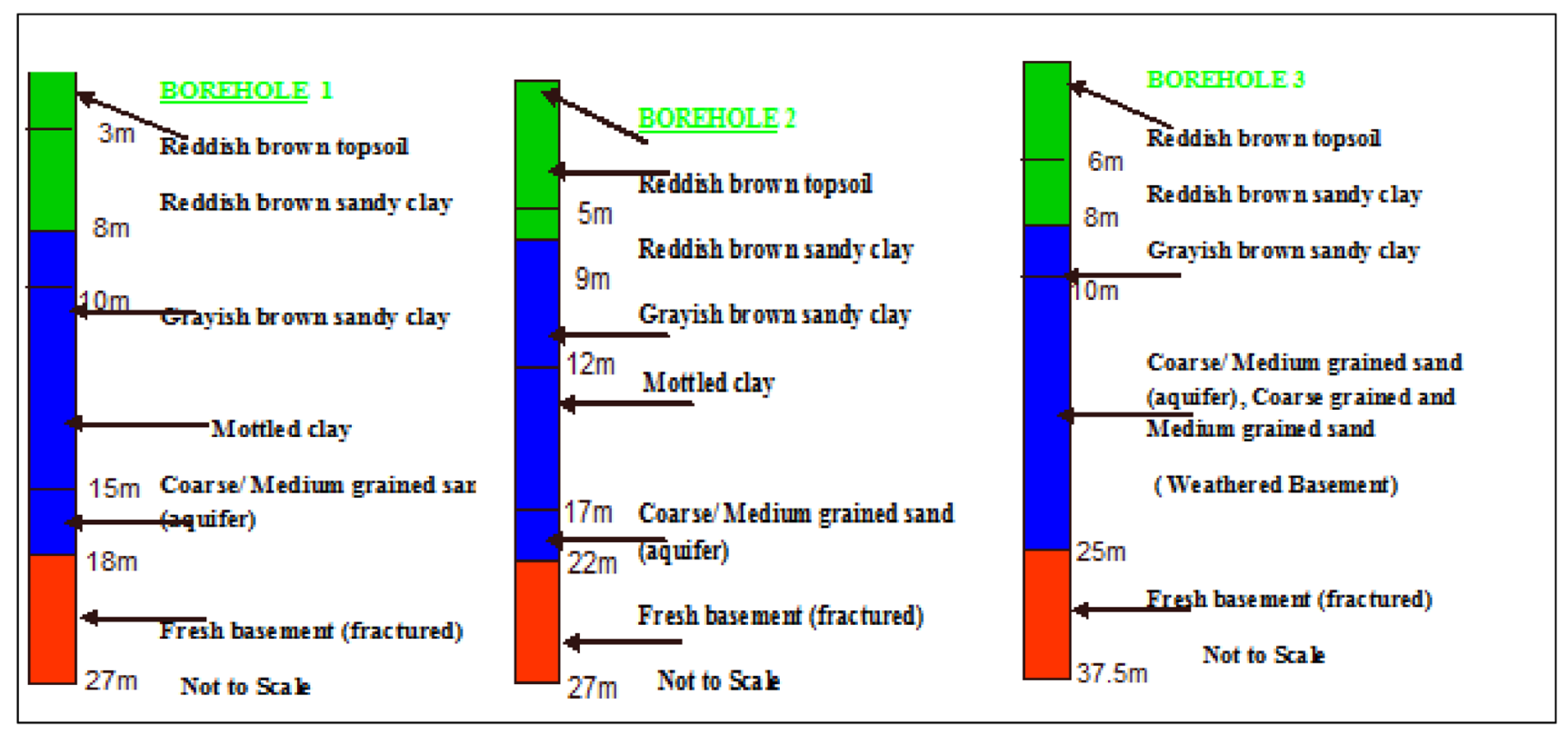

Fig. 5 Borehole logs used to constrain Profiles 1-3 (After Hydro-Skill Engineering Services Limited [13]) 
the section suggests that there was no uniform weathering across the area. The thickness of the weathered materials from a distance of about 50 to $110 \mathrm{~m}$ along the section and depth of about $22 \mathrm{~m}$ from the surface vise-a-vise the

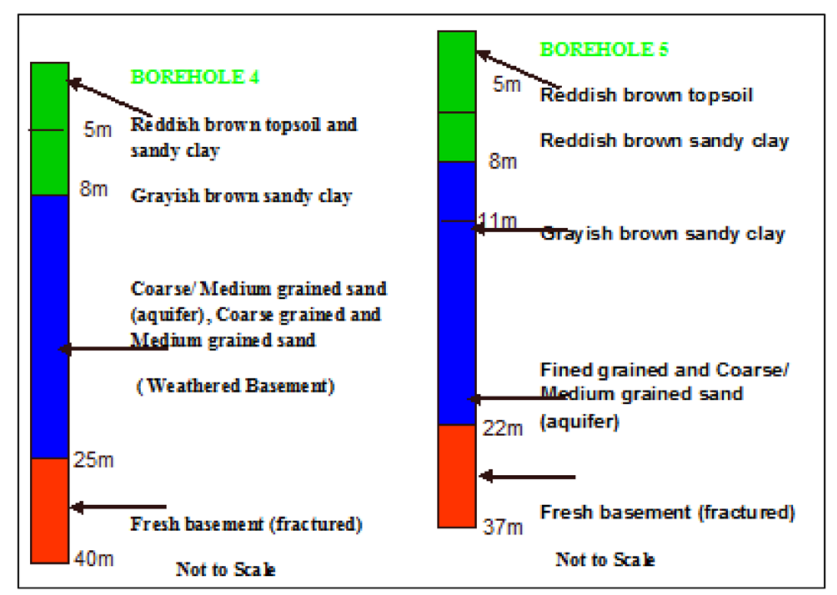

Fig. 6 Borehole logs used to constrain Profiles 4 and 5 (After HydroSkill Engineering Services Limited [13]) basement rise at the beginning and toward the end of the profile will create a conducive environment for the accumulation of groundwater in this area (Fig. 6).

Figure 7 shows the 2D geoelectric section obtained on profile 2, oriented northwest-southeast of the Akenzua Hall. When correlated with the lithology log in Fig. 5, the area is also characterized by three layers. The topsoil along this line is made up of reddish-brown topsoil and sandy clay characterized by resistivity values ranging between 10 and $80 \Omega \mathrm{m}$. The thickness of this layer varies between 3 and $9 \mathrm{~m}$ along the profile and also clearly shows a relatively larger thickness of weathered materials between 0 and $100 \mathrm{~m}$ along the line and depth of $29.3 \mathrm{~m}$. like profile 1 , the $2 D$ image also revealed the basement rise in the second half of the profile as depicted by the high resistivity structure along 130-165 m along the line. The second layer with varying thickness values ranging between 13 and $20 \mathrm{~m}$ is characterized by resistivity values between 10 and $650 \Omega \mathrm{m}$. The first half of this section, beginning from 0 to $100 \mathrm{~m}$ along the line and depth of $29.3 \mathrm{~m}$, indicates lower resistivity values $(<19.3-70 \Omega \mathrm{m})$. This is, as a result, the presence of weathered materials (made up of

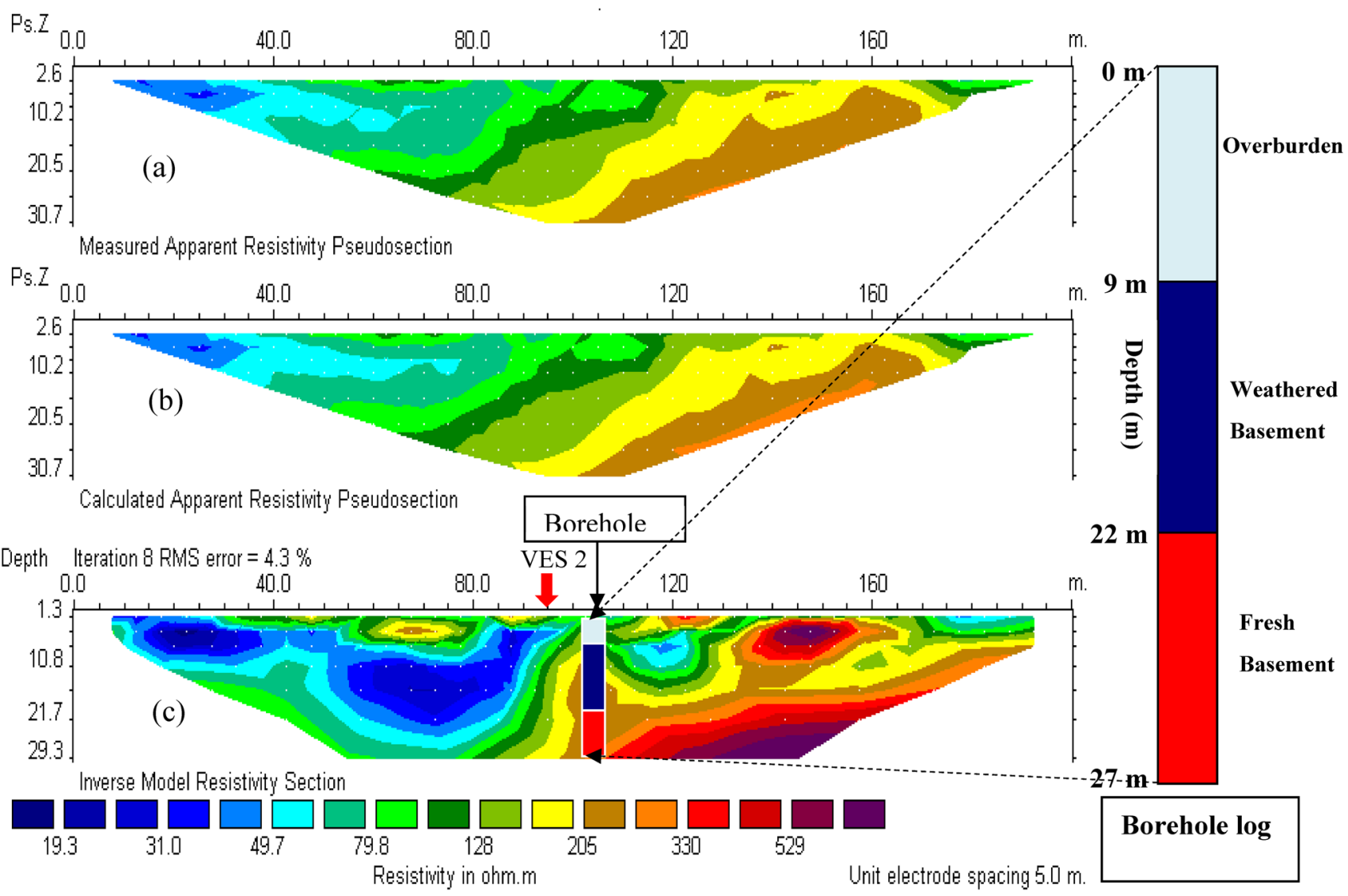

Fig. 7 Electrical imaging line on profile 2, with borehole-log at the centre (a) observed data plotted as a contoured pseudosection (b) pseudosection computed from the model and (c) image showing true formation resistivity and true depth 
medium-grained sand and greyish brown sandy clay) and is interpreted as the hydrogeological unit. The $2 \mathrm{D}$ resistivity model nicely picked up this considerable groundwater resource (thickness of aquifer) due to the deepening of the basement rock occurring within the first half of the model. The third layer along this profile is interpreted as the basement structure directly underlying the weathered basement rock. It has varying resistivity values ranging between 230 and $550 \Omega \mathrm{m}$. The high resistivity signature occurs around the 130-160 m mark along the profile length. The $2 \mathrm{D}$ section shows the increase in the depth to the bedrock at $0 \mathrm{~m}$ and $100 \mathrm{~m}$ laterally along the profile at a depth of $29.3 \mathrm{~m}$ from the surface of the earth. Tying the geologic sections in Table 1 with all the resistivity models (geoelectric sections), there is a strong correlation between the interpreted layers of rock on the geoelectric sections and the geologic section in terms of the number of layers (with a difference of $\pm 4 \mathrm{~m}$ ), thicknesses of each layer and the types of materials present.

Figure 8 shows the $2 \mathrm{D}$ resistivity model acquired along profile 3 with northeast-southwest orientation around the Amina Hall. The profile revealed only two layers when tied with the borehole log for the area (Fig. 5). But the first half of the profile from 0 to $100 \mathrm{~m}$ along the line revealed three layers. The first layer with resistivity values ranging between 28 and $100 \Omega \mathrm{m}$ and varying depth of between 5 and $8 \mathrm{~m}$ is characterized by reddish-brown topsoil and sandy clay from a distance of 82-200 $\mathrm{m}$ along the profile. Unlike profiles 2 and 3 , the topsoil from the beginning of the profile to a distance of about $82 \mathrm{~m}$, and depth range of 1.3-5 $\mathrm{m}$ shows relatively higher resistivity values $(169-400 \Omega \mathrm{m})$. This is attributed to dry clayey sand. The second layer with resistivity values ranging between 4 and $60 \Omega \mathrm{m}$ from a distance of about $40-200 \mathrm{~m}$ and varying depth range of between 6.4 and $19.8 \mathrm{~m}$ is interpreted as the weathered basement rocks characterized by coarse to medium-grained sand. This zone is inferred as the prospect and potential groundwater resource for this area. Interestingly, the 2D image clearly revealed some sort of stratigraphic pinch out associated with the second layer on the first half of the profile. The third layer on this part is characterized by a basement rise from a distance of about $5-100 \mathrm{~m}$ and varying depth range of between 6.5 and $18 \mathrm{~m}$.

Profiles 4 and 5 were obtained around the Alex and Suleiman Halls and are shown in Figs. 9 and 10, respectively. The lines were oriented along the northwest-southeast and northeast southwest direction, respectively. When correlated with the available lithology logs shown in Fig. 6, the models revealed the existence of three layers. The 2D model on profile 4 shows high resistivity bedrock overlain by materials of varying resistivity. The topsoil here is characterized by sandy clayey material of very low resistivity $(4-20 \Omega \mathrm{m}$ ) along the profile length, with a varying thickness of between 4 and $8 \mathrm{~m}$. Underlying the topsoil is the weathered basement unit with varying thickness of between 6 and $21.3 \mathrm{~m}$ and characterized by greyish-brown sandy clay, fine to medium-grained sand, coarse-grained

Table 1 Lithology, aquifer and geologic section around the study area

\begin{tabular}{|c|c|c|c|c|c|}
\hline Profiles & Subsurface materials & Depth range $(\mathrm{m})$ & Thickness (m) & Interpreted lithology & $\begin{array}{l}\text { Hydrogeologic } \\
\text { characteristics }\end{array}$ \\
\hline \multirow[t]{3}{*}{1} & Overburden & $0-8$ & 8 & Reddish brown top soil & - \\
\hline & Weathered basement & $8-18$ & 10 & Greyish brown sandy clay & Aquifer \\
\hline & Fresh Basement & $18-25$ & & Coarse porphyritic granite & - \\
\hline \multirow[t]{3}{*}{2} & Overburden & $0-9$ & 9 & Reddish brown top soil and sandy clay & - \\
\hline & Weathered basement & $9-22$ & 13 & $\begin{array}{l}\text { Greyish brown sandy clay, Mottled Clay and Coarse/ } \\
\text { Medium grained sand }\end{array}$ & Aquifer \\
\hline & Fresh basement & $22-27$ & 9 & Coarse porphyritic granite & - \\
\hline \multirow[t]{3}{*}{3} & Overburden & $0-8$ & 8 & Reddish brown top soil and sandy clay & \\
\hline & Weathered basement & $8-25$ & 17 & $\begin{array}{l}\text { Greyish brown sandy clay, Coarse/fine/medium grained } \\
\text { sand and medium grained sand }\end{array}$ & Aquifer \\
\hline & Fractured basement & $25-37.5$ & & Coarse/fine/medium grained sand & - \\
\hline \multirow[t]{3}{*}{4} & Overburden & $0-5$ & 5 & Reddish brown top soil and sandy clay & \\
\hline & Weathered basement & $5-25$ & 20 & $\begin{array}{l}\text { Greyish brown sandy clay, Fine/medium grained sand, } \\
\text { Coarse grained sand and medium grained sand }\end{array}$ & Aquifer \\
\hline & Fractured basement & $25-40$ & & Coarse/medium grained sand & - \\
\hline \multirow[t]{3}{*}{5} & Overburden & $0-8$ & 8 & Reddish brown top soil and sandy clay & \\
\hline & Weathered basement & $7-25$ & 18 & $\begin{array}{l}\text { Greyish brown sandy clay, Fine grained sand and Coarse/ } \\
\text { medium grained sand }\end{array}$ & Aquifer \\
\hline & Fractured basement & $22-37$ & & Coarse/medium grained sand & - \\
\hline
\end{tabular}




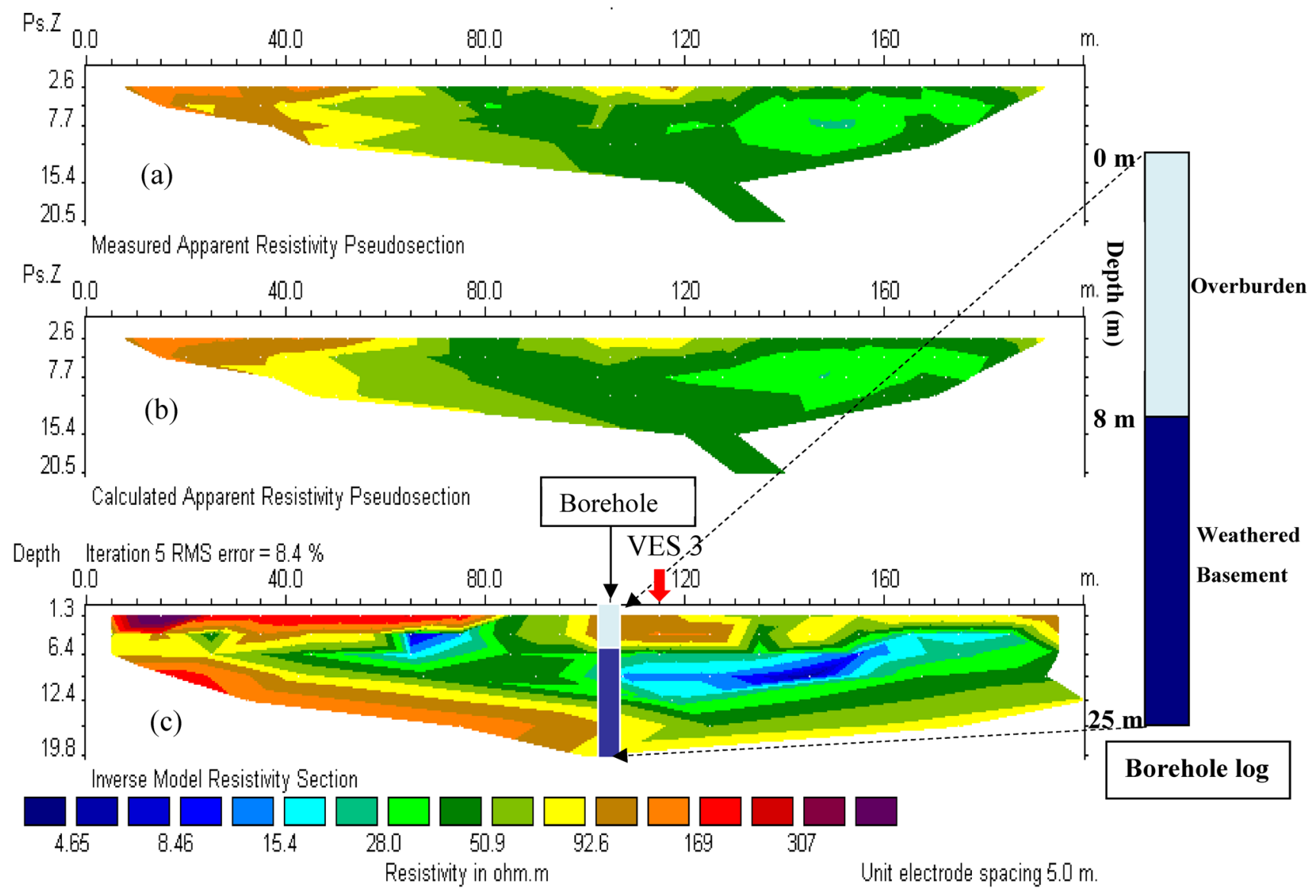

Fig. 8 Electrical imaging line on profile 3, with borehole-log at the centre (a) observed data plotted as a contoured pseudosection (b) pseudosection computed from the model and (c) image showing true formation resistivity and true depth

sand, and medium-grained sand. Due to the intense weathering of the rock layer, the rock unit is inferred as the prospect and potential groundwater reserve, which can be exploited. The substantial thickness of this material at the centre makes there the most appropriate location to cite a borehole. This zone is made up of resistivity values ranging between 20 and $70 \Omega \mathrm{m}$. The third layer around this area marked with relatively higher resistivity values (100 and $250 \Omega \mathrm{m}$ ) is interpreted as the fresh basement rock.

The 2D resistivity image obtained along profile 5 (Fig. 10.) exhibits varying resistivity values ranging between 4 and $170 \Omega \mathrm{m}$. The region along the surface with relatively high resistivity values $(24-170 \Omega \mathrm{m})$ and depth from the surface to approximately $8 \mathrm{~m}$ coincide with dry sand. The water-bearing units (weathered basement) occur within the second layer with varying thickness of between 8 and $24 \mathrm{~m}$. The resistivity value of this zone varies between $<10.7$ and $90 \Omega \mathrm{m}$ and attributed to the presence of clayey and sandy materials of varying textures. The thickness of this layer is seen to increase from the end of the profile to the beginning of the line and therefore suggests that the appropriate location to site a borehole is within the first quarter of the profile. The third layer which is of relatively higher resistivity greater than $100 \Omega \mathrm{m}$ is probably a fractured basement.

Figure 11 shows the interpreted VES curves obtained at the centre of the five $2 \mathrm{D}$ resistivity profiles. While VES 1 is an A-type curve with the second layer interpreted as an aquifer (Fig. 11a), VES 2-VES 5 are H-type curves with the second layers exhibiting relatively lower resistivity values (5-24 $\Omega \mathrm{m}$ ) which may have been caused by the presence of groundwater (Fig. 11b-e). The third layer underlying the study area, with relatively higher resistivity (114.5-265.6 $\Omega \mathrm{m})$, could be attributed to the presence of the fractured/basement complex rocks.

\section{Discussion of results}

By careful examination of the $2 \mathrm{D}$ resistivity models (resistivity values), and using available geological control, some useful information was extracted from the sections generated from this study. The resistivity sections provided a 


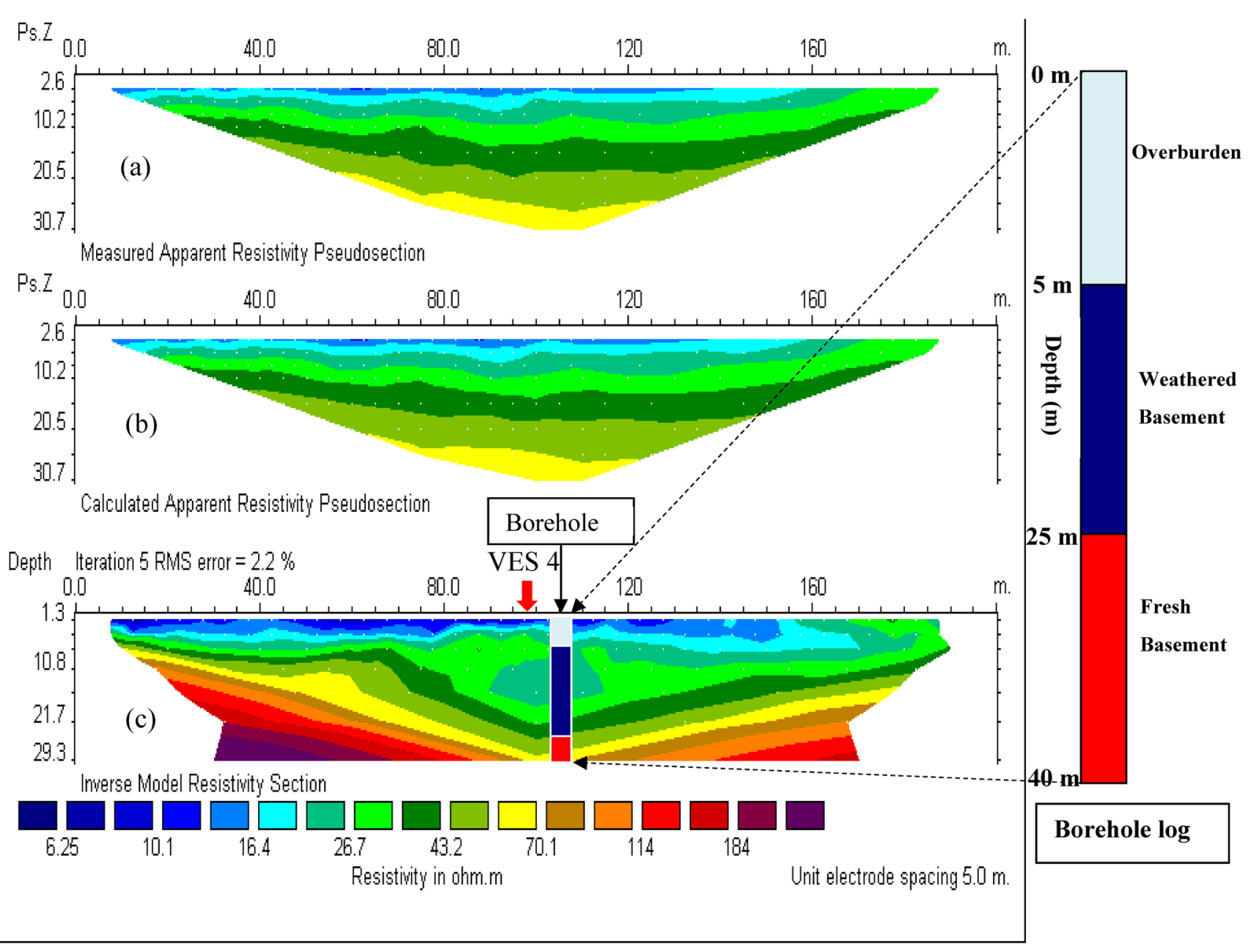

Fig. 9 Electrical imaging line on profile 4, with borehole-log at the centre (a) observed data plotted as a contoured pseudosection (b) pseudosection computed from the model and (c) image showing true formation resistivity and true depth

visible image of the thickness of regolith (weathered overburden) and the distribution of various other litho-facies within the study area. The thickness of the overburden and the resistivity of rock materials are important hydrogeologic parameters in groundwater development in a basement terrain. The reason for this is that water flows into the saturated zone through the overburden [4]. The layer saturated with water is characterized by low resistivity ranging between 4 and $90.6 \Omega \mathrm{m}$, with varying thickness values and occurring within the second layer, whereas the unsaturated rocks were usually characterized by high resistivity values. Omosuyi et al. [23] developed a scheme for ranking of groundwater potential as a function of weathered basement resistivity. This classification shows that resistivity range between 20 and $100 \Omega \mathrm{m}$ is related to excellent weathering and groundwater potential. Comparing this with the result of this study ( 4 and $90.6 \Omega \mathrm{m}$ ), it implies that the weathered basement rocks have great potentials for groundwater occurrence.
Traditionally, the VES technique is used to investigate the occurrence of the vertical distribution of the sedimentary sequences of rock, the thickness of the water-bearing aquifers, and in detecting the subsurface geologic features that give a clue to the presence of groundwater. The VES data obtained from this study provided information which compliments results from the $2 \mathrm{D}$ resistivity technique. When compared with the 2D models, the results from the two experiments were found to be in good agreement and therefore validate the results from the $2 \mathrm{D}$ resistivity survey of the study area. The resistivity distribution within the subsurface, the number of layers, the thicknesses of the various layers encountered, and their depths of occurrence averagely coincided. Most of the field curves exhibit a similar pattern.

In terms of aquifer thickness, the 2D and VES geoelectric sections along all the profiles also provided useful information about the groundwater potential. Olayinka and Olorunfemi, [21], proposed values of overburden thickness ranging 


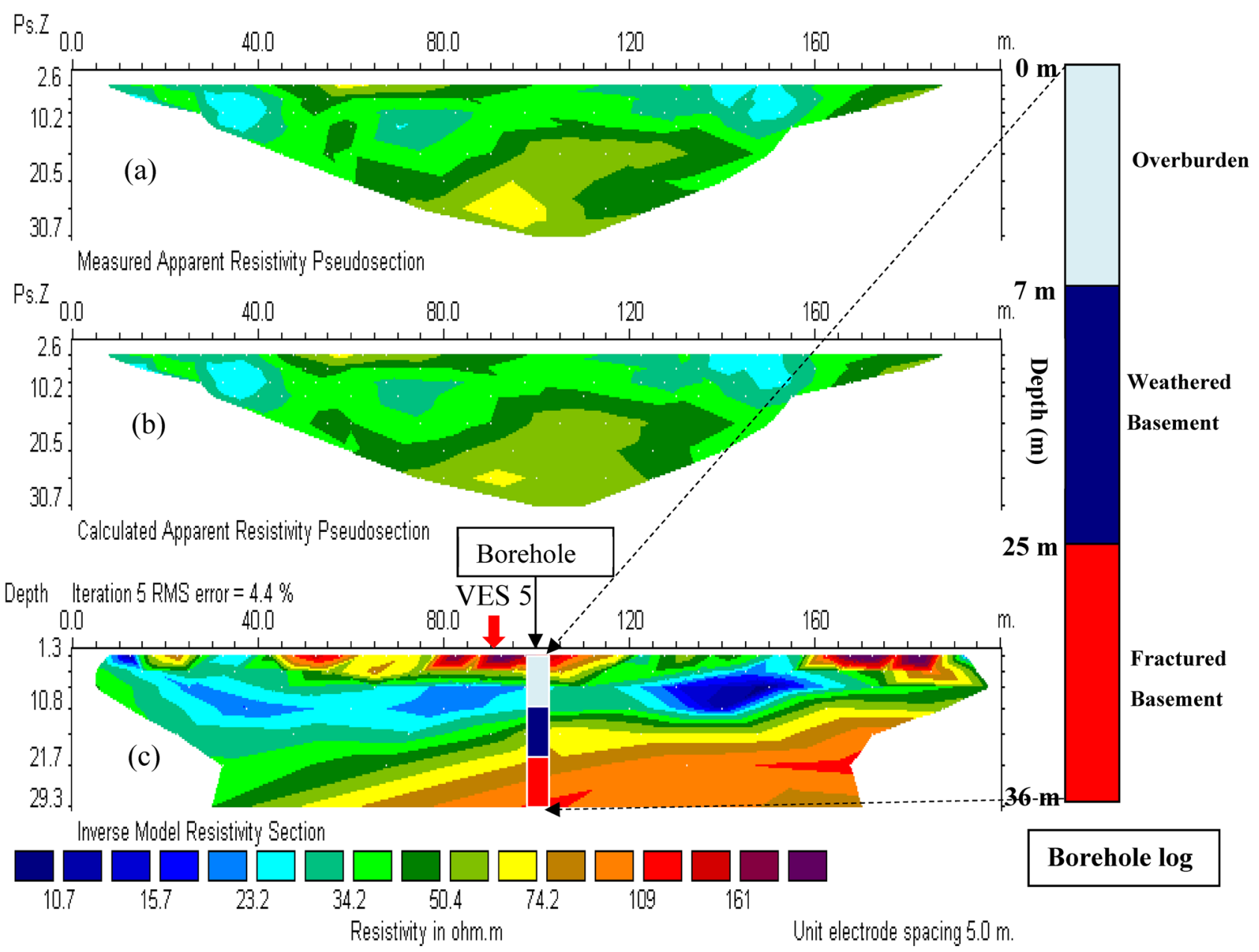

Fig. 10 Electrical imaging line on profile 5, with borehole-log at the centre (a) observed data plotted as a contoured pseudosection (b) pseudosection computed from the model and (c) image showing true formation resistivity and true depth

between 20 and $30 \mathrm{~m}$ for productive wells. Similarly, they also prescribed a minimum overburden thickness of $25 \mathrm{~m}$ for viable groundwater abstraction. The results from this research indicated that the thicknesses of the weathered regoliths favourable for groundwater exploration vary from $13.4 \mathrm{~m}$ around the Amina Hall, $16.7 \mathrm{~m}$ northeast-southwest of Akenzua Hall, 21.2 m northwest-southeast of Akenzua Hall, $24.3 \mathrm{~m}$ around Alex Hall and $25.3 \mathrm{~m}$ around the Suleiman Hall. This very essential parameter reveals the groundwater potential of the study area and therefore suggests that groundwater can be developed and harnessed for use by the University but with a greater yield around the Alex (24.3 $\mathrm{m}$ aquifer thickness) and Suleiman Halls (25.3 m aquifer thickness) when compared with the other locations.

The imaging technique has proved to be robust in the subsurface geophysical investigation. Most of the electrical images generated correlated well with the results of borehole drilled in the investigated area. Thicknesses of water-bearing rocks play important roles in the accumulation of groundwater, and based on the result obtained from this work, there is a variation of the thickness of sediments within the study area and the water-bearing horizon around the Alex and Suleiman halls are significantly thick and can support groundwater production.

\section{Conclusion}

The integration of 2D resistivity imaging and VES survey produced reliable results revealing the actual subsurface geologic characteristics of the study area. The VES data obtained from this study provided information which compliments results from the $2 \mathrm{D}$ resistivity technique. The results were able to establish the most suitable locations for the siting of boreholes on the University Campus. Out of the 5 profiles investigated, profiles 4 and 5 (around 

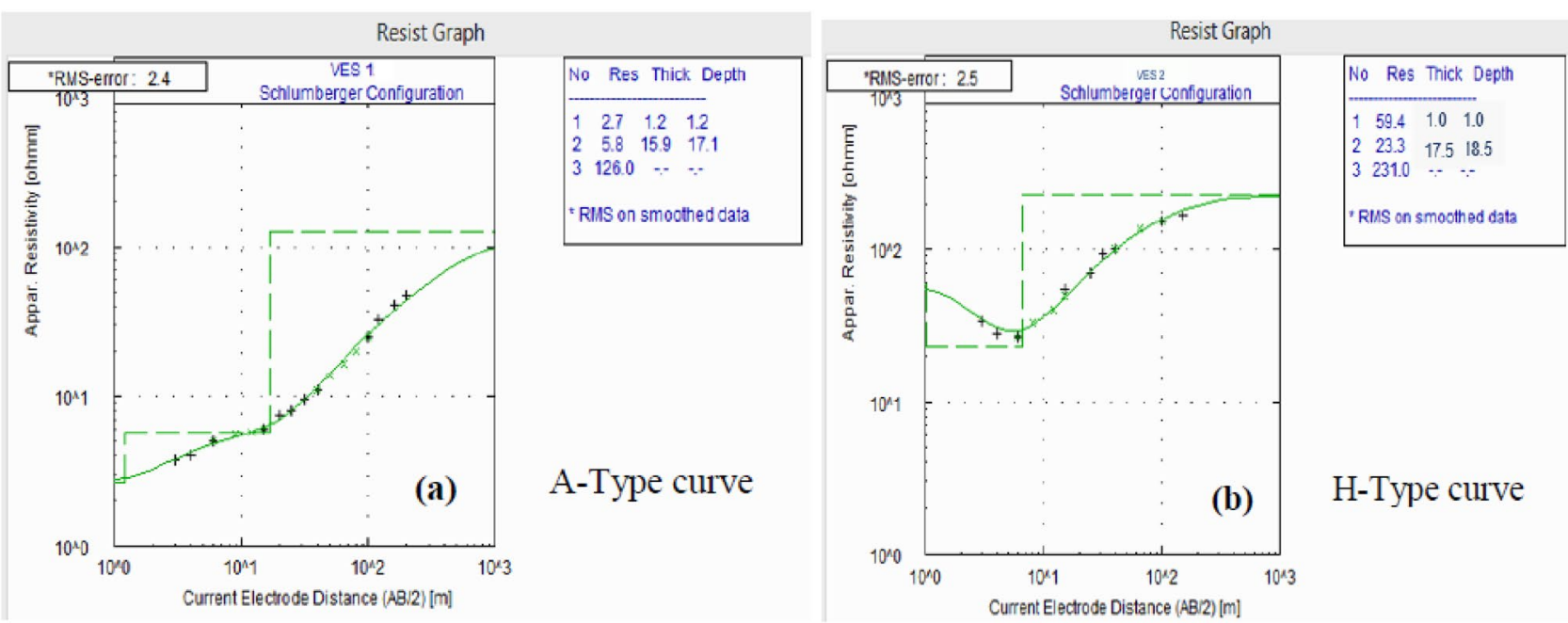

A-Type curve
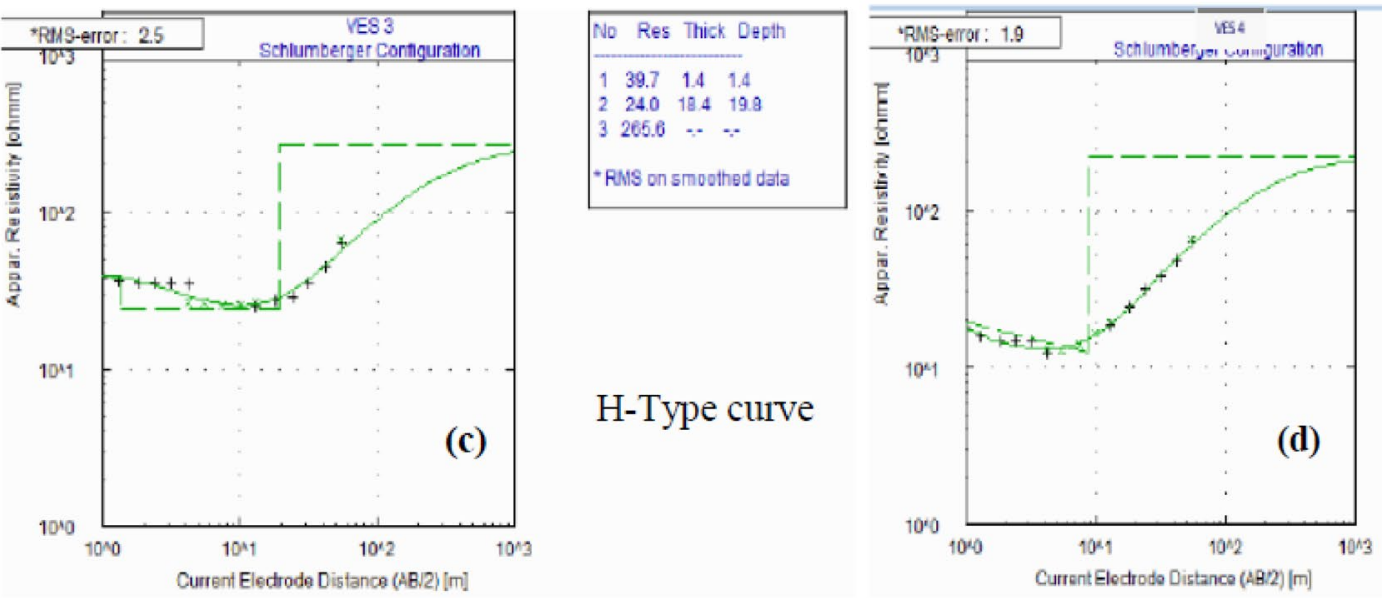

\begin{tabular}{|lcccc|}
\hline No & Res & Thick Depth \\
\hline 1 & 22.9 & 0.5 & 0.5 \\
2 & 12.4 & 19.2 & 19.7 \\
3 & 219.5 & $\cdot$ & $\cdot$ \\
"RuS on smoothed data \\
\hline
\end{tabular}

H-Type curve

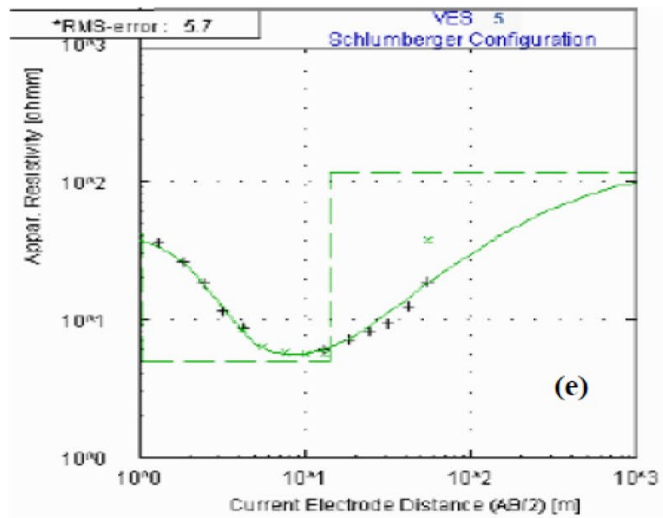

$$
\begin{array}{|lccc}
\text { No } & \text { Ros } & \text { Thick Depth } \\
\hline 1 & 42.3 & 1.0 & 1.0 \\
2 & 5.0 & 18.0 & 19.0 \\
3 & 114.5 & \cdots & \cdots \\
\text { * Fus on smo othed data }
\end{array}
$$

H-Type curve

H-Type curve

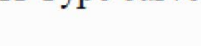

\section{H-Type curve}

Fig. 11 Sounding curves obtained along the five 2D resistivity imaging lines (a-e)

Suleiman and Alex Halls), located towards the northwestsoutheast and northeast-southwest of the study area, indicated relatively large thicknesses of weathered materials overlying the basement rocks when compared with the other profiles. These hydrogeologic units constitute the aquifer in the area and vary between 13.4 and $25.3 \mathrm{~m}$ of thickness. Due to the significant thicknesses of the aquifers around the Alex and Suleiman halls, they are considered more promising for groundwater development.

Evaluation of the results and lithology logs around the area also revealed the presence of clayey materials in various proportions. Clay swells and shrinks as it absorbs and releases water, this repeated swelling and shrinking could be responsible for the structural failure of some of 
the buildings (tilting and sinking) seen within the environment where this survey was carried out. Therefore, there is a need for a more extensive geophysical and geotechnical investigations of building foundation to avoid future structural failures around the study area.

Acknowledgements The authors are grateful to the International Programme in the Physical Sciences (IPPS), Uppsala University, Sweden, for partial funding of this research. Also to covenant University for logistic Support.

\section{Compliance with ethical standards}

Conflict of interest On behalf of all authors, the corresponding author states that there is no conflict of interest.

Open Access This article is licensed under a Creative Commons Attribution 4.0 International License, which permits use, sharing, adaptation, distribution and reproduction in any medium or format, as long as you give appropriate credit to the original author(s) and the source, provide a link to the Creative Commons licence, and indicate if changes were made. The images or other third party material in this article are included in the article's Creative Commons licence, unless indicated otherwise in a credit line to the material. If material is not included in the article's Creative Commons licence and your intended use is not permitted by statutory regulation or exceeds the permitted use, you will need to obtain permission directly from the copyright holder. To view a copy of this licence, visit http://creativecommons .org/licenses/by/4.0\%.

\section{References}

1. Adanu EA (1989). Hydrogeology of Basement Complex terrain in the Zaria: Kaduna area (Nigeria). PhD Thesis, TU, Berlin, 75p

2. Afuwai GC (2014) Geophysical investigation of groundwater potential of Kongo Campus, A.B.U., Zaria-Nigeria. Eur J Edu Stud $7(1): 1$

3. Akhtar IR, Mohd AAN, Mohd HZA (2018) Application of electrical resistivity method (ERM) in groundwater exploration. J Phys Conf Ser 995:012094. https://doi.org/10.1088/17426596/995/1/012094

4. Akindeji OF (2020) Groundwater aquifer potential using electrical resistivity method and porosity calculation: a case study. NRIAG J Astron Geophys 9(1):168-175. https://doi. org/10.1080/20909977.2020.1728955

5. Alagbe SA, (1987) Hydrogeology of the River Kangimi catchment area, Kaduna State. Unpubl. M.Sc. Thesis, Dept. of Geology, Ahmadu Bello University, 168p

6. Ameloko AA, Ayolabi AA (2018) Geophysical assessment for vertical leachate migration profile and physicochemical study of groundwater around the Olusosun dumpsite Lagos, south west Nigeria. Appl Water Sci 8:142

7. Ameloko AA, Ayolabi AE, Akinmosin A (2018) Time dependent electrical resistivity tomography and seasonal variation assessment of groundwater around the Olusosun Dumpsite Lagos, South-West, Nigeria. J Afr Earth Sc 147:243-253

8. Ameloko AA, Omali AO (2011) Groundwater exploration with D.C resistivity method in Maigamo area of Kubanni river basin Zaria Nigeria. World Rural Obs 3(1):72-81
9. Aminu Z, Jaiyeoba IA, Bello AL, Iguisi EO (2013) An assessment of changing land use/cover types in Zaria area, Kaduna state, Nigeria. Niger Geogr J 9(1):57-77

10. Ayolabi EA, Adedeji JK, Oladapo IM (2004) A geoelectric mapping of ljapo, Akure Southwest Nigeria and its hydrogeological implications. Global J Pure Appl Sci 10:441-446

11. Danladi GG (1985). Appraisal of hydrogeophysical investigations in shallow basement areas of Zaria, Kaduna State. Unpubl. MSc. Thesis, Dept. of Geology, Ahmadu Bello University, 114p

12. Eigbefo C (1978) Hydrology of the Kubanni Drainage Basin, Zaria. Unpublished M.Sc. thesis, Department of Physics, Ahmadu Bello University, Zaria

13. Hydro-Skills Engineering Services Limited (2006) Report of Geophysical Survey for Borehole Drillings in Ahmadu Bello University, Zaria. Submitted to ABUCONS Royal Shelters, Ahmadu Bello University, Zaria

14. Inichinbia S, Sule PO (2018) 2D Geo-electrical imaging for groundwater exploration in Shika, along Zaria-Funtua Road North of Ahmadu Bello University Main Campus, Samaru. Zaria J Appl Sci Environ Manag 22(4):609-612

15. Kowal J, Omolokun AO (1970) The hydrology of small catchment Basin at Samaru, Nigeria. Niger Agric J 7(1):27-40

16. Loke MH, Barker RD (1996) Rapid least-squares inversion of apparent resistivity pseudosection by quasi-Newton method. Geophys Prospect 44:131-152

17. Mathiazhagan M, Selvakumar T, Madhavi G (2015) Groundwater abstraction andcontamination studies at Thiruvidanthai village, along East Coast Road in Chennai using electrical resistivity method with geochemical analysis. J Coas Sci 2:8-12

18. McCurry P (1973). The geology of degree sheet 21, Zaria. Unpublished M.Sc. Thesis. Department of Geology, Ahmadu Bello University, Zaria

19. Murmu P, Kumar M, Lal D, Sonker I, Singh SK (2019) Delineation of groundwater potential zones using geospatial techniques and analytical hierarchy process in Dumka district, Jharkhand. India Groundw Sustain Dev 9:100239

20. Oden MI, Ogunleye PO, Udinmwen E (2015) Measurement of Pan-African strain in Zaria Precambrian Granite Batholith, Northwestern Nigeria. J App Geol Geophys 3(1):21-30

21. Olayinka Al, Olorunfemi MO (1992) Determination of geoelectric characteristics in Okene area and implications for borehole siting. J Min Geol 28:403-411

22. Olorunfemi MO, Okhue ET (1992) Hydrogeologic and geologic significance of a geoelectric survey at lle-Ife. Niger J Min Geol 28(2):221-229

23. Omosuyi GO, Adeyemo A, Adegoke AO (2007) Investigation of groundwater prospect using electromagnetic and geoelectric sounding at Afunbiowo. Pac J Sci Technol 8:172-182

24. Oyawoye MO (1964). Geology of the Nigerian basement complex. J Niger Min Metall Soc 87-102

25. Sajeena S, Abdul Hakkim VM, Kurrien EK (2014) Identification of groundwater prospective zones using geoelectrical and electromagnetic surveys. Int J Eng Invent 3(6):17-21

Publisher's Note Springer Nature remains neutral with regard to jurisdictional claims in published maps and institutional affiliations. 